\title{
Ramsey, Pragmatism, and the Vienna Circle
}

Cheryl Misak

\section{OpenEdition}

\section{Journals}

Electronic version

URL: http://journals.openedition.org/ejpap/1504

DOI: 10.4000/ejpap.1504

ISSN: 2036-4091

\section{Publisher}

Associazione Pragma

\section{Electronic reference}

Cheryl Misak, «Ramsey, Pragmatism, and the Vienna Circle », European Journal of Pragmatism and American Philosophy [Online], XI-1 | 2019, Online since 19 July 2019, connection on 21 July 2019. URL : http://journals.openedition.org/ejpap/1504; DOI : 10.4000/ejpap.1504

This text was automatically generated on 21 July 2019.

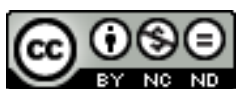

Author retains copyright and grants the European Journal of Pragmatism and American Philosophy right of first publication with the work simultaneously licensed under a Creative Commons AttributionNonCommercial-NoDerivatives 4.0 International License. 


\title{
Ramsey, Pragmatism, and the Vienna Circle
}

\author{
Cheryl Misak
}

\section{AUTHOR'S NOTE}

Much of this paper is drawn from Misak 2020. I thank Christoph Limbeck-Lilineau, the reviewers of this volume, and the participants of the Vienna conference on European Pragmatism for their helpful comments on an earlier draft.

\section{Ramsey's Reputation}

1 Frank Ramsey is often aligned with the Vienna Circle. He was listed in the Circle's 1929 "Manifesto" as one of those "sympathetic" to their mission (Carnap, Hahn \& Neurath 1973 [1929]: 318). It might be said that being listed in the Manifesto didn't mean much: a number of people were invoked there, without, it seems, their foreknowledge or consent, and the document itself was controversial within the Circle. But the idea that Ramsey was on board with the Vienna Circle's mission wasn't confined to their official announcement. In the 1950s, Carnap and Hempel would take Ramsey's paper "Theories," posthumously published in 1931, to be an important contribution to their own attempts to construct scientific theories from observation and logic. Hans-Johann Glock has recently said that Ramsey was "pre-eminent" amongst the school of Cambridge analysts, who shared with the Vienna Circle and Wittgenstein the idea that "simple propositions occur in complex ones only in such a way that the truth-value of the latter depends solely on those of the former." According to Glock, the Cambridge analyst's “attempts to reduce all meaningful propositions to truth-functional constructions out of elementary propositions referring to sense-data were no more successful than Russell's fledgling attempts and Carnap's heroic effort in Der logische Aufbau der Welt" (2008: 80-1). 
2 His connection with Wittgenstein's Tractatus is largely responsible for the perception that Ramsey was aligned with the Vienna Circle. Wittgenstein's biographer, Ray Monk, says that Ramsey was "unable to follow [Wittgenstein] in his radical departures from the theory of the Tractatus" and suggests that Ramsey may be the stupid man in the following dream, which Wittgenstein reported to his diary in 1929: ${ }^{1}$

This morning I dreamt: I had a long time ago commissioned someone to make me a water-wheel and now I no longer wanted it but he was still working on it. The wheel lay there and it was bad; it was notched all around, perhaps in order to put the blades in (as in the motor of a steam turbine). He explained to me what a tiresome task it was, and I thought: I had ordered a straightforward paddle-wheel, which would have been simple to make. The thought tormented me that the man was too stupid to explain to him or to make a better wheel, and that I could do nothing but leave him to it. I thought: I have to live with people to whom I cannot make myself understood. That is a thought that I actually do have often. At the same time with the feeling that it is my own fault. (Monk 1990: 276)

3 While Wittgenstein never thought himself signed up with the Vienna Circle, he certainly had a sustained engagement with them from 1929 till the mid-1930s. And he was quick to accuse Waismann and Carnap of plagiarizing his ideas. Wittgenstein had, in step with the Circle, reduced all meaningful language to an elementary language of simple, basic statements that hook on to simple objects in the world. The Circle took the Tractatus to be the "deepest and truest" work of "the new philosophy" (Schlick 1927).

Ramsey died in January 1930, shortly after Wittgenstein's dream and the Vienna Circle's claiming of him. He was just 26 years old, robbed of the opportunity to develop and sum up his work, and to put it in careful relation to the traditions in which he operated. It falls to others to piece together the record and put it straight. For in fact, Ramsey argued, against Wittgenstein and the Vienna Circle, that it was impossible to reduce all meaningful propositions to a primary language of experience and logic. He was not aligned with the Vienna Circle's mission, but rather, was a self-described pragmatist. His persistent pragmatist objections to the "picture theory" of meaning and truth were responsible for Wittgenstein's turn away from the Tractatus and towards his latter approach, with its emphasis on the primacy of practice and the idea that meaning is use. ${ }^{2}$ And Ramsey's objections were of the kind that would make some members of the Vienna Circle liberalize their own positions after his death.

5 Ramsey of course had things in common with the Vienna Circle, such as an interest in the foundations of mathematics and the relationship between propositions and reality, and a facility with logical methods. It's not surprising that he was interested in talking philosophy with them. ${ }^{3}$ Their problems were his problems, even if he didn't agree with their solutions. And Ramsey was indeed initially engaged with Wittgenstein's project, and tried to improve some aspects of it. ${ }^{4}$ But even as an undergraduate, as early as 1923, he was arguing that the primary or elementary language was not sufficient to account for the great variety of legitimate and truth-apt beliefs. We shall see that, while Ramsey did indeed have an influence on the Vienna Circle, he ended up pulling against, not toward, their project.

\section{Introducing the Tractatus to the Circle}

6 In 1921, at the age of 18, Ramsey was asked by the publisher C. K. Ogden to translate the manuscript that Wittgenstein had finished during the First World War. Russell and 
Keynes had managed to get it out of war-torn Europe and, with the help of Dorothy Wrinch, get it printed, full of errors and without any revision by its author. That was in a German journal, Annalen der Naturphilosophie. Wittgenstein was keen to have it come out in English. Ramsey was well-versed in logic and in Russell's philosophy, and was keen to do it. He went to Miss Pate's secretarial agency in the winter of 1921-22 and directly read this difficult manuscript in English - off the Annalen proofs - to a shorthand writer, who then typed it up. After much correspondence, with Wittgenstein making corrections to his own thinking and to the translation, it was published in 1922, with the German and Ramsey's English translation side-by-side. Ogden took the credit for the translation, merely expressing "his indebtedness to Mr F. P. Ramsey, of Trinity College, Cambridge, for assistance both with the translation and in the preparation of the book for the press" (Wittgenstein 1922). No one at the time, however, took anyone but Ramsey to have done the job. ${ }^{5}$

7 In September 1923 Ramsey went to the small town near Vienna, where Wittgenstein was teaching school, and the two finally met. For two weeks, they went over the Tractatus line by line, for 5 hours a day. At this point, Ramsey was the only person who really understood the Tractatus. (Wittgenstein had declared that Moore, Russell, and Frege didn't understand him.) Ramsey's critical notice of the book was in press at Mind, and he was relieved, during his marathon conversation with Wittgenstein, to find that he still thought it was basically right.

In March 1924, Ramsey went to Vienna for six months, both to be psychoanalyzed and to spend more time talking with Wittgenstein. Gretl Stonborough, Wittgenstein's sister, introduced him to Schlick. Ramsey's first impression of Schlick remained steady throughout his life: "he didn't seem to me much of a philosopher, but a very nice man." 6 The Cambridge mathematician Max Newman was in Vienna as well, and introduced him to Hans Hahn, who granted Ramsey permission to use the University library and invited him to attend his seminar on Theory of Functions of a Complex Variable. Ramsey didn't attend Hahn's seminar, but he did rue that he wouldn't be in Vienna the following year, when Hahn was to give a seminar on Russell and Whitehead's Principia Mathematica.

It was during this 1924 visit that the emerging Vienna Circle (and the Berlin Circle) was properly introduced to the Tractatus. ${ }^{7}$ Carnap had been in New York in 1923, when some mathematicians told him about Russell's influence on the new "mathematical philosophy." Carnap wrote to Reichenbach about the people connected to this new philosophy. The list was long. It included Wittgenstein, Keynes, and Broad, but gave no particular importance to Wittgenstein. Reichenbach immediately forwarded Carnap's letter to Schlick, and asked Schlick to write to Russell (with no mention of Wittgenstein) to see if Russell might be interested in being involved in a journal they were planning. Schlick then wrote to Reichenbach and noted that one of those new mathematical philosophers was nearby: "Wittgenstein, whose book is edited by Russell, lives here close to Vienna." ${ }^{\prime}$ It seems that Schlick didn't yet have a copy of the revised and translated Tractatus, for he didn't know that Russell was not in fact the book's editor, but merely wrote the Introduction. His University Library had one copy of the substandard Annalen version, but it isn't clear whether Schlick had looked at it at the time he was exchanging these letters in 1923.

10 That would change in the summer of 1924, when Schlick met Ramsey. Schlick wrote to Reichenbach on August 5. He was no longer merely mentioning Wittgenstein, but was fired up about him. He had now read the Annalen version: 
Do you know the "Tractatus-logico-philosophicus" from L. Wittgenstein, which appeared in the Annals of Natural Philosophy and which has been edited by Russell in a book version in German and English? The author lives close to Vienna, and is highly original, also as a human being; the more one studies his treatise, the more one is impressed by it. The English translator, a mathematician from Cambridge, whom I met in the summer, is also a very intelligent and sophisticated mind. ${ }^{9}$

Schlick then wrote to Wittgenstein on Christmas Day, expressing his admiration of the Tractatus and his desire to meet its author. He told him that the mathematician, Kurt Reidemeister had recently given a talk at the University of Vienna about the Tractatus, and mentioned that "last summer I had the pleasure to meet Mr. Ramsey, the translator of your work, during his last stay in Vienna."10 Schlick asked Wittgenstein how he and Reidemeister might get their own copies of the Tractatus. Wittgenstein wrote back, saying he himself didn't have spares, but Ramsey “would certainly be kind enough to arrange for some copies." ${ }^{\prime 11}$ By early 1925, the Circle was in possession of the Ramsey translation.

The Vienna Circle read the Tractatus with care and attention, steadily until 1927, taking it to be a kind of founding document of their movement. While there was some plurality already in the view of the members of the Vienna Circle, it's fair enough to say that they differed from Wittgenstein in that they explicitly said that the basic statements were observation statements, whereas Wittgenstein was vague on this matter. And the Circle ignored Wittgenstein's insistence that the propositions of ethics and religion were without sense, yet more important than the propositions which had sense. These differences aside, the Circle took Wittgenstein, not unreasonably, to be a kindred spirit. One insight of Wittgenstein's was especially important. That was the idea that the truths of logic are tautologies, true, come what may, and hence exempt from the empirical standard of meaningfulness. Their interest in Ramsey in 1924 was very much related to this point.

\section{Logic and Mathematics as Tautology}

Ramsey wrote "The Foundations of Mathematics," his undergraduate thesis, while he was in Vienna and published it in the 1925 Proceedings of the London Mathematical Society. In it, he tried to fix the "defects" in Principia Mathematica. At this point, Ramsey was on board with Russell's logicist project and spent most of the paper trying to repair Russell's solution to logicism's biggest problem - the set theoretic paradoxes. He argued for a modification of Russell's theory of types that could do without the Axiom of Reducibility.

The Vienna Circle was open to new ideas, from Cambridge especially. They had devoured Principia and the Tractatus. "The Foundation of Mathematics" provided the next discussion point. Ramsey sent Schlick the published paper, writing "With the compliments of the author" on the first page. Carnap transcribed parts of it and Schlick scribbled comments on the whole of his copy. We can see from Carnap's Tagebuch that the Circle talked about the paper for two weeks in January 1927 and then intermittently right through to 1929. The first entry in January notes: "Waismann told us about the Ramsey paper." The next week: "We talked about Wittgenstein and Ramsey. Very interesting." ${ }^{12}$

15 What they found very interesting was Ramsey's extension of Wittgenstein's idea of tautology. Like all empiricists, the members of the Vienna Circle struggled to say why the statements of logic and mathematics are legitimate, given that they don't satisfy their 
observational criterion of meaningfulness. Hume had invoked a too-convenient separation of matters of fact and relations of ideas, with statements concerning the latter (including mathematical and logical statements) simply being exempt from the observational criterion. Mill had made an unsuccessful attempt to treat mathematics as an observable science. The Vienna Circle had been happy to find part of their own answer in the Tractatus. The truths of logic fit with any state of the world. Hence, they make no claims about the world and do not need to be verified by the world. But what about mathematics? Wittgenstein held that mathematical concepts consist of purely syntactic or formal equations. He thought they didn't have sense, but not in the way that logic lacks sense.

Ramsey claimed that Wittgenstein's position was "obviously a ridiculously narrow view of mathematics," as it was confined to simple arithmetic (FM: 180). Ramsey argued that mathematical truths, like logical truths, are tautologies. Russell wanted to build up the whole edifice of mathematics from primitive principles, and Ramsey thought he should do it by taking primitive logical and mathematical propositions to be tautologies, so that everything that he built up will be necessarily true.

17 As far as the Circle was concerned, the two moves taken together - first logic, then mathematics, being seen as tautologies - were a fundamental turning point in philosophy..$^{13} \mathrm{Hahn}$ was especially clear that the tautological character of mathematics is absolutely essential: "If this position can be made out [...] the existence of mathematics is then also compatible with the empiricist position." (1980 [1931]: 34). Ramsey had given them a nice way out of a difficult problem.

\section{The Dispute Between Ramsey and Wittgenstein about Identity}

Wittgenstein himself staunchly resisted the suggestion. His resistance manifested itself in a dispute with Ramsey about the nature of identity statements, a dispute that involved the Circle, at least as minor players in the drama. On June 20,1927, Wittgenstein, Carnap, and Waismann met with Schlick at his house. It was the first time that Carnap had met Wittgenstein. They discussed Ramsey's paper, and Wittgenstein registered an objection to the account of identity in it. Carnap wrote in his in his diary afterwards that Wittgenstein was very interesting and original. But he thought that his objections to Ramsey were such that he took a rapid or impulsive position and then tried to find arguments for that assessment. One week later, on the 27th, they all met again, this time at Carnap's house. On this second meeting, Wittgenstein dictated a letter to Schlick, for delivery to Ramsey. (Wittgenstein was giving Ramsey the silent treatment, because of an argument they had had in 1925 about the value of Freud.) Carnap typed the letter, and Wittgenstein then wrote the opening and closing paragraphs by hand. He addressed it to "Dear Mr. Ramsey" and it asked Mr. Ramsey to send a response to the logical point not directly to him, but via Schlick. ${ }^{14}$

Ramsey considered not following Wittgenstein's instructions to write only to Schlick. He wrote two draft replies to Wittgenstein himself, saying that Schlick "won't know whether my answer is any good." He also said that Schlick's 1918 Allgemeine Erkenntnislehre (The General Theory of Knowledge) contained some "sad rubbish," but was willing to consider the 
possibility that "he may have got cleverer since then." In the end, he obeyed his difficult friend and sent his reply via Schlick.

Wittgenstein had an identity statement being part of mathematics, and hence consisting of "equations" and "therefore pseudo-propositions." Ramsey thought that identity statements were true, but trivially so - they were tautologies..$^{15}$ The debate, conducted in its entirety is this two-letter exchange, would soon be moot. Immediately after the publication of "The Foundations of Mathematics," Ramsey expressed doubts about it, and in 1929, he would abandon the logicist project and start actively exploring intuitionism. He wrote two long notes in August 1929, "Principles of Finitest Mathematics" and "The Formal Structure of Intuitionist Mathematics," in which he opted mostly for Weyl's introduction rules and arrived at his own substitution rules. ${ }^{16}$ Wittgenstein, who returned to Cambridge in January 1929, was also at that point interested in intuitionism. Together, they would become attracted to what Ramsey in "The Foundations of Mathematics" had called "the Bolshevik menace of Brouwer and Weyl" (FM: 219). When Braithwaite published a collection of Ramsey's papers, posthumously in 1931, he sounded the alert in introduction that Ramsey had abandoned logicism for intutionism. It took Russell by surprise. ${ }^{17}$

Also in 1931, it seems not yet having read Braithwaite's introduction, Carnap registered a worry about Ramsey's logicism..$^{18}$ He said that Ramsey "courageously" tried to solve Russell's problems by arguing that the circles of the set theoretic paradoxes are harmless, not vicious. Carnap thought that Ramsey's solution was "certainly tempting," but "we should not let ourselves be seduced by it." It smacked too much of "a platonic realm of ideas which exist in themselves independently of if and how finite human beings are able to think them." While intuitionism, he said, has been called "anthropological mathematics," Ramsey's logicist theory might well be called "theological mathematics" (1983 [1931]: 39). Ramsey's notes about intuitionism were only published in $1991^{19}$ and the Circle never registered that Ramsey had moved away from the conception of mathematics as tautology - the conception of mathematics that was so useful to them.

\section{5. "Facts and Propositions"}

While Ramsey's move away from logicism was only noticed after his death, evidence that he wasn't aligned with Circle's project certainly existed in at least one paper the Circle read during his lifetime. "Facts and Propositions" was published in the 1927 Proceedings of the Aristotelian Society, and was mentioned in the Manifesto as one of Ramsey's sympathetic papers. In it, he utilized Wittgenstein's conception of tautology in a novel way. Wittgenstein had argued (in Ramsey's words) that "a logical truth excludes no possibility and so expresses no attitude of belief at all" (FP: 47). Ramsey built on this idea to arrive at one of his most fruitful insights. Beliefs exclude possibilities, and that's how we can a) individuate belief and b) measure partial belief. What it is to believe a proposition is, in large part, to behave in certain ways, and to take various possibilities as alive or dead. This pragmatist position holds that it is of the essence of a belief that it has a causal impact on our actions.

23 In this paper, Ramsey made a remark about truth that many have mistaken for a "deflationary" or "redundancy" theory, in which talk of truth is a superfluous add-on and can be simply dropped: 
there is really no separate problem of truth but merely a linguistic muddle [...] "It is true that Caesar was murdered" means no more than that Caesar was murdered, and "It is false that Caesar was murdered" means that Caesar was not murdered [...]. (FP: 38) 1923. It would have alerted them to Ramsey's worries about Wittgenstein's project, and by extension, their own. 
Ramsey had remarked in his Critical Notice that Russell's introduction may not be "an infallible guide to Mr. Wittgenstein's meaning," for Russell said that Wittgenstein was concerned with a logically perfect language. But Wittgenstein, Ramsey wrote, seems to maintain that his doctrines apply to ordinary languages in spite of appearances to the contrary. [...] This is obviously an important point, for this wider application greatly increases the interest and diminishes the plausibility of any thesis such as that which Mr. Russell declares to be perhaps the most fundamental in Mr. Wittgenstein's theory; that "In order that a certain sentence should assert a certain fact there must [...] be something in common between the structure of the sentence and the structure of the fact." (CN: 465)

Ramsey agreed with Wittgenstein that his doctrines should apply to ordinary language, but the linchpin for the pressing, and eventually fatal, problems Ramsey raised for the Tractatus is that they failed to do so.

Ramsey noted that there are two things at work in the Tractatus. One is "the non-mystical deductions" that occupy most of the text - the arguing in detail for "the necessity of something in common between the picture and the world" (CN: 468). The other consists of indicating or gesturing at all the things that are "intrinsically impossible to discuss" (CN: 468). He saw difficulties arising for both. That is, he threw spanners into the works of Wittgenstein's elaborate machinery (the picture theory of meaning) and he worried about the main contention of the book, as Wittgenstein himself saw it (the distinction between saying and showing).

The idea of representation in the Tractatus is that the picture has the same structure, or the same logical form, as reality. Ramsey's most general objection, ${ }^{21}$ which hangs over the whole of Wittgenstein's project, is this:

But it is evident that, to say the least, this definition is very incomplete; it can be applied literally only in one case, that of the completely analysed elementary proposition. (CN: 469)

Ramsey made note of some propositions that cannot be reduced to elementary sentences that correspond to simple objects. For instance, what about those containing logical connectives, such as ' $\sim$ ' and ' $v$ ', which do not have objects to represent? Wittgenstein treated these as operators on propositions, and thought that we could use such symbols to express things that we cannot state, but can only show. Ramsey thought that this subverted the simple isomorphic structure that Wittgenstein was supposed to be putting in place. The negation operator ' $\sim$ ' illustrates the problem perfectly. The Tractatus gives us an account of representation, understanding, and truth that is essentially positive. ${ }^{22}$ To understand a proposition is to see how things are if it is true. All elementary propositions depict positive facts, and the world is fully described by one unique set of such propositions. Ramsey noted that it would be "absurd" to represent $\sim(a R b)$ as mirroring a negative fact, and was not mollified by Wittgenstein's rendering of ' $\sim$ ' as saying that that there is no such combination between objects or things.

But it was not just the logical connectives that couldn't be pictured in the elementary language. Ramsey announced: "We must now turn to one of the most interesting of Mr. Wittgenstein's theories, that there are certain things which cannot be said but only shown, and these constitute the Mystical." (CN: 472). He registered in the "Critical Notice" what would later become a more fully-formed unease about the saying/showing distinction. Wittgenstein's form of representation is itself an "elusive entity which is intrinsically impossible to discuss." That is, Wittgenstein's own discussion of what 
representation is goes beyond elementary propositions. Wittgenstein of course saw this, saying that his philosophical discussion had to be used like a ladder and then kicked away. Ramsey thought this an unacceptable move. His conclusion in the "Critical Notice" is that "we cannot be satisfied with a theory that deals only with elementary propositions." Later he would put the point more sharply: "But what we can't say we can't say, and we can't whistle it either." (GPC: 146).

It should be clear that already in 1923, Ramsey was not trying to get the logical analyst view right. Much of what is important about language cannot be reduced to a primary language, and we cannot sweep the secondary language under a rug as unsayable (Wittgenstein) or merely instrumental (some of the members of the Vienna Circle).

\section{What about "Theories"?} from the philosophy of science" (ОT: 35). A problem for the Vienna Circle was that there seems to be no meaning to our beliefs about unobservable entities such as electrons, or even the backside of the moon being made of green cheese. For we can't directly observe them. Moreover, there is also no way of accounting for how the theory of mass, for instance, changes or is improved upon. On the explicit definition account of scientific theories, it seems that every time the theory changes, we change the meanings of the terms in the older versions or refer to new entities. As Ramsey put it, "if we proceed by explicit definition we cannot add to our theory without changing the definitions, and so the meaning of the whole" (T: 130). He takes it as obvious that we need to be able to explain how a concept both evolves and retains its meaning, and how a theory grows. Thus, "the dictionary alone does not suffice," unless we are happy with a finite, primary 
system much less rich than the theory itself (T: 122ff). All "useful theories" must have "more degrees of freedom" than the primary system. There would be no point in having a scientific theory unless it went beyond a catalogue of the current facts. Ramsey, that is, showed that Carnap's project, as Ramsey understood it from the Aufbau, could be completed, but would be no good at all.

He then instructed the empiricist on how to think of scientific theories, without employing explicit definitions. In keeping with his pragmatism, he highlighted the consequences of belief. A theory is a system of judgments or beliefs, whose consequences will meet the future successfully or not. We employ the theory as a whole, as a shorthand expression of all those judgments, and can thus make sense of unobservable things, such as the back of the moon:

If our theory allows as a possibility that we might go there or find out in any other way, then it has meaning. If not, not; i.e. our theory of the moon is very relevant, not merely our theory of things in general. (T: 134)

Our theory of the moon, and of solid bodies in space, will tell us something about the likely constitution of the moon's far side - the whole theory gives meaning to beliefs about the unobservable part of the moon and determines whether they are true or false.

Ramsey then made a new move, the idea that would later excite Carnap and Hempel. He argued that we can elucidate the role of theoretical terms such as "electron" in a long and complex formal sentence which contains both theoretical and observational terms. The sentence will start with: "There are things which we call electrons, which [...]," and then will go on to tell a story about those electrons. We assume there are electrons for the sake of the story, just as we assume there is a girl when we listen to a story that starts "Once upon a time there was a girl, who [...]." Any additions to the theory are to be made within the scope of the quantifier that says that there exists at least one electron. That is, the theory can evolve while still being about the original entities. Additions to the theory of electrons are not "strictly propositions by themselves just as the different sentences in a story beginning 'Once upon a time' have not complete meanings and so are not propositions by themselves" (T: 131). That is, they are not beliefs that are true or false in the strict sense of the primary language. We commit ourselves to the existence of the entities in our theory, knowing that if it gets overthrown, so will our commitment to its entities. In the meantime, we use the theory.

This innovation is entirely consistent with Ramsey's pragmatist view of definitions in 1929: definitions "are to give at least our future meaning, and not merely to give any pretty way of obtaining a certain structure" (P: 1). Definitions tell us how to go on using a term by making more precise the vague and complex concept it stands for. While this view of definitions and theories didn't serve the 1929 Vienna Circle well, it would be attractive once the Circle had given up on the strict reductionist project, largely due to those objections from the philosophy of science.

We can see from Carnap's copy of the Braithwaite volume, that he read "Theories" in the early 1930s carefully. ${ }^{23}$ Hempel heard of Ramsey's idea much later, from Braithwaite's 1946 Tarner Lectures. ${ }^{24}$ In the early 1950s Carnap and Hempel started to employ Ramsey's existentially quantified sentences as a tool in their attempts to show how the world can be constructed from experience. ${ }^{25}$ The origin of the idea had become hazy in Carnap's mind, only to become clear again when in 1958 he read a draft of Hempel's "The Theoretician's Dilemma: A study in the logic of theory construction," in which Hempel coined the term "Ramsey Sentence." Carnap wrote to Hempel, saying that his paper had 
prompted him to go back to the Braithwaite volume and see that he had "neatly underlined" important passages in "Theories," and expressing his gratitude for being prevented from presenting Ramsey's idea as his own. ${ }^{26}$ In 1966, Carnap sent Braithwaite his Philosophical Foundations of Physics, which had a chapter titled "The Ramsey Sentence."

That Carnap wasn't ready to employ Ramsey's innovation in 1929 is unsurprising. At that time, as Keynes put it, Ramsey had been "departing [...] from the formal and objective treatment." That treatment marked Carnap's work at the time. Ramsey and Wittgenstein had started off by helping Russell to perfect the system of Principia Mathematica. But, Keynes said, the effect was

gradually to empty it of content and to reduce it more and more to mere dry bones, until finally it seemed to exclude not only all experience, but most of the principles [...] of reasonable thought. Wittgenstein's solution was to regard everything else as a sort of inspired nonsense, having great value indeed for the individual, but incapable of being exactly discussed. Ramsey's reaction was towards what he himself described as a sort of pragmatism [...]. Thus he was led to consider "human logic" as distinguished from "formal logic." (1972 [1931]: 338)

Keynes was right. By 1929, Ramsey had found the deductive approach a sack of dry bones. A central point in "Theories" is that questions of usage - in this case, how we use a scientific theory - are more important than questions of metaphysics. The metaphysics of logical atomism does not provide enough to go on in real life and real science. Theories are true or false, not in the strict, atomist sense, but in a holist, pragmatist sense. The way Ramsey dealt with scientific theories (and everything else that went beyond the primary system) was very much against the spirit of the late 1920s Vienna Circle. It was to adopt a pragmatist account truth or falsity, an account that asked whether the consequences of beliefs meet the future well.

\section{Ramsey on Wittgenstein and the Vienna Circle, 1929}

Wittgenstein returned to Cambridge, after his self-imposed exile, on January 17, 1929. Ramsey died on January 19, 1930. In that year, the two were locked in an almost daily conversation. One might call it a battle over the right approach to philosophy. As Ramsey put it, in a 1929 paper titled "Philosophy," one method, "Ludwig's," is to

construct a logic, and do all our philosophical analysis entirely unselfconsciously, thinking all the time of the facts and not about our thinking about them, deciding what we mean without any reference to the nature of meanings. (P:5)

Ramsey's pragmatist method, in contrast, directed us to the human facts, not the facts somehow abstracted from all human understanding. He thought that we will often run into terms "we cannot define, but [...] can [only] explain the way in which they are used" (P: 5). He admitted to having once been under the sway of Wittgenstein's conception of philosophy:

I used to worry myself about the nature of philosophy through excessive scholasticism. I could not see how we could understand a word and not be able to recognize whether a proposed definition of it was or was not correct. I did not realize the vagueness of the whole idea of understanding, the reference it involves to a multitude of performances any of which may fail and require to be restored. (P: 1-2) 

But in 1929, Wittgenstein was still trying to construct an ideal definition in a perfect language. Ramsey thought that an instance of scholasticism, "the essence of which is treating what is vague as if it were precise and trying to fit it into an exact logical category" (P: 7)

He opened a draft of "Philosophy" with an explicit reprimand to Wittgenstein:

Philosophy must be of some use and we must take it seriously; it must clear our thoughts and so our actions, Otherwise it is mere chatter. or else it is a disposition we have to check [...] i.e. the chief proposition of philosophy is that philosophy is nonsense. And again we must then take seriously that it is nonsense, and not pretend, as Wittgenstein does, that it is important nonsense! ${ }^{27}$

1 We must avoid the "absurd position" of the child in the following dialogue:

"Say breakfast." “Can't." "What can't you say?" "Can't say breakfast." (P: 6)

Wittgenstein maintained that philosophy is nonsense and should be abandoned. Ramsey's objection in "Philosophy" was twofold. First, Wittgenstein cannot argue for a particular view of the nature of meaning, a consequence of which is that the very argument for that view is meaningless. We do in fact understand Wittgenstein's philosophical argument. It is not a ladder that, once climbed, needs to be kicked away. The same point holds for the Vienna Circle's dismissal of metaphysics. Second, this kind of philosophy is impoverished. If, as Wittgenstein thinks, philosophy's task is to take the propositions of science and ordinary life and "exhibit them in a logical system with primitive terms and definitions," philosophy really is of not much use at all (P: 1$)$. In a note, Ramsey said:

The standardisation of the colours of beer is not philosophy, but in a sense it is an improvement in notation, and a clarification of thought. (NPPM: 55)

Philosophy must be more than an improvement in notation.

It is clear that in 1929, Ramsey's approach, and his rebellion against Wittgenstein and the Vienna Circle, was in full swing. He says in another note:

We cannot really picture the world as disconnected selves; the selves we know are in the world. What we can't do we can't do and it's no good trying. Philosophy comes from not understanding the logic of our language; but the logic of our language is not what Wittgenstein thought. The pictures we make to ourselves are not pictures of facts. (NPPM: 51)

5 If a proposition is a picture of the world, disconnected from any reference to the self whose picture it is, then we are totally vulnerable to skepticism or solipsism. How are we to bridge the gap between ourselves and that world? How we can even make claims about that world? Ludwig's primary world "contains no thought." 28 If we want to understand the world, we must not neglect the "subjective side" (P: 6). Carnap, Ramsey thought, made the same "mistake":

Solipsism in the ordinary sense in which as e.g. in Carnap the primary world consists of my experiences past present and future will not do. For this primary world is the world about which I am now thinking [...]. (NPPM: 66) existence of all manner of objects, if we are to think about the world at all. Carnap's mistake was to reduce a patch of red, say, into, say, infinite classes of points, thus destroying its being my patch or your patch.

Ramsey never wrote more about the Vienna Circle. He and Carnap never met. But his mind was on Carnap during his fatal illness. A month before he died, Ramsey wrote to 
Schlick about the Aufbau, expressing doubts about Carnap's attempt to reconstruct the world out of a primary language:

I feel very guilty that I've not yet written a review of Carnap's book, which is really inexcusable. I found it very interesting, though some things I thought certainly wrong and others I felt very doubtful about. ${ }^{29}$

Ramsey wanted to get "clear about the truth of these things" himself before writing about the "merits" and the doubtful points in Carnap's book.

\section{Conclusion}

Ramsey cannot be seen as sympathetic to the Vienna Circle, as he knew it. During his lifetime the Circle's project was to reduce all meaningful language to a certainly true empirical foundation. He did not know that more liberal and pragmatist versions would come after his death. In the early 1930s, the Vienna Circle started to see that a correspondence theory of truth collided with their verificationism - how can we verify that which is utterly independent of us? And "the problem from the philosophy of science" about unobservable entities and theory change also pressed in on them. Philipp Frank, as early as 1930, suggested that pragmatism was the answer:

The physicist in his own scientific activity has never employed any other concept of truth than that of pragmatism. The "agreement of thoughts with their object," which the school philosophy requires, cannot be established by any concrete experiment [...] In reality, physicists compare only experiences with other experiences. They test the truth of a theory by what it has become customary to call “agreements." (1949 [1930]: 101-2)

60 Just like Ramsey, Frank employs the term "school philosophy" as a description of the project he now thinks is to be avoided in favour of the pragmatist theory of truth. In this way, and others, too complex to enter into here, ${ }^{30}$ many in the Circle moved closer to Ramsey, as their position fractured and evolved into various camps. Had Carnap been ready for Ramsey's pragmatism when he first read the Braithwaite volume in the early 1930s, the Circle might well have taken Ramsey's position as a model, instead of realizing only in the 1950s that he had important things to offer a liberalized empiricist philosophy.

\section{BIBLIOGRAPHY}

BRAITHWAITE Richard, (1931), “Editor's Introduction," in Frank P. Ramsey, The Foundations of Mathematics and other Logical Essays, London, Routledge and Kegan Paul, ix-xiv.

CARNAP Rudolf, (1958), "Beobachtungssprache und Theoretische Sprache," Dialectica, 12/3-4, 236-348.

CARNAP Rudolf, (1983 [1931]), “The Logicist Foundations of Mathematics.” Originally published in Erkenntnis. Reprinted in Philosophy of Mathematics: Selected Readings, 2nd ed., ed. Paul Benacerraf \& Hilary Putnam, Cambridge, Cambridge University Press, 41-52. 
CARNAP Rudolf, haHn Hans \& Otto NEURATH, (1973 [1929]), "The Scientific Conception of the World: The Vienna Circle," in Marie Neurath \& Robert S. Cohen (eds), Empiricism and Sociology, Dordrecht, D. Reidel, 299-318.

FRANK Philipp, (1949 [1930]), "Physical Theories of the Twentieth Century and School Philosophy," in Modern Science and Its Philosophy, Cambridge, MA, Harvard University Press, 90-121.

Galavotti Maria Carla (ed.), (1991), Frank Plumpton Ramsey, Notes on Philosophy, Probability and Mathematics, Naples, Bibliopolis. Cited as NPPM.

GLOCK Hans-Johann, (2008), "The Development of Analytic Philosophy: Wittgenstein and After," in Dermot Moran (ed.), The Routledge Companion to Twentieth Century Philosophy, London, Routledge, 76-117.

HAHN Hans, (1980 [1931]), "Discussion about the Foundations of Mathematics," in Id., Empiricism, Logic and Mathematics, Vienna Circle Collection, vol. 13, ed. by Brian McGuinness, Dordrecht, Springer.

HEMPEL Carl G., (1958), “The theoretician's dilemma: A study in the logic of theory construction," Minnesota Studies in the Philosophy of Science, 2, 173-226.

KEYNES John Maynard, (1972 [1931]), "Review of the Foundations of Mathematics," The New Statesman, 3 October, 1931. Reprinted in Essays in Biography. The Collected Writings of John Maynard Keynes, vol. 10, ed. by Elizabeth Johnson \& Donald E. Moggridge, London, Macmillan, 336-9.

MACBRIDE Fraser, (2018), On the Genealogy of Universals: The Metaphysical Origins of Analytic Philosophy , New York, Oxford University Press.

MCGUINNESS Brian (ed.), (2012), Wittgenstein in Cambridge: Letters and Documents 1911-1951, Oxford, Blackwell.

METHVen Steven J., (2015), Frank Ramsey and the Realistic Spirit, London, Palgrave Macmillan. MONK Ray, (1990), Ludwig Wittgenstein: The Duty of Genius, New York, The Free Press.

MISAK Cheryl, (2016), Cambridge Pragmatism: From Peirce and James to Ramsey and Wittgenstein, Oxford, Oxford University Press.

MISAK Cheryl, (2020), Frank Ramsey: A Sheer Excess of Powers, Oxford, Oxford University Press. PSILLOS Stathis, (1999), Scientific Realism: How Science Tracks Truth, London, Routledge. RAMSEY Frank P., (1923), "Critical Notice, Tractatus Logico-Philosophicus, by Ludwig Wittgenstein," Mind, 32/128, 465-78. Cited as CN.

RAMSEY Frank P., (1925), “Universal,” Mind, 34/136, 401-17. Reprinted in Ramsey (1990), 8-30.

RAMSEY Frank P., (1926), "The Foundations of Mathematics," Proceedings of the London Mathematical Society, s2-25/1, 338-84. Reprinted in Ramsey (1990), 164-224. Cited as FM.

RAMSEY Frank P., (1927), “Facts and Propositions,” Reprinted in Ramsey (1990), 34-51. Cited as FP. RAMSEY Frank P., (1929b), “General Propositions and Causality,” in Ramsey (1990), 45-164. Cited as GPC.

RAMSEY Frank P., (1929c), “Theories,” in Ramsey (1990), 112-37. Cited as T.

RAMSEY Frank P., (1929d), “Philosophy,” in Ramsey (1990), 1-8. Cited as P. 
RAMSEY Frank P., (1990), Philosophical Papers, ed. by David Hugh Mellor, Cambridge, Cambridge University Press.

RAMSEY Frank P., (1991 [1930]), On Truth, ed. by Nicholas Rescher \& Ulrich Majer, Dordrecht, Kluwer. Cited as OT.

RUSSELL Bertrand, (1931), "Critical Notice of The Foundations of Mathematics and Other Logical Essays, Frank Plumpton Ramsey," Mind, 40/160, 476-82.

SCHLICK Moritz, (1927), Letter to Albert Einstein, July 14, 1927, Einstein Collection, Hebrew

University, EC 21-599.

WitTGENSTEIN Ludwig, (1922), Tractatus Logico-Philosophicus, trans. C. K. Ogden, London, Routledge and Kegan Paul.

\section{NOTES}

1. Monk also thinks it possible that Wittgenstein took himself to be the one who kept tinkering with the broken machine.

2. For the full argument about Ramsey's influence on Wittgenstein, see Misak 2016, and 2020.

3. Ramsey wrote to Schlick in the spring of 1928: "I am thinking of coming to Vienna almost immediately, and wonder whether, if I did, you or any of your circle would be able to spare a little time to talk philosophy with me. If you could, I should be extremely grateful as I get very little stimulus here and make no progress." (The Vienna Circle Archive, Noord-Hollands Archief: 114-Ram-2.) Schlick was away during Ramsey's proposed dates, but invited him to come and stay some other time.

4. For instance, his 1925 "Universals" is an extension and deepening of Wittgenstein's position that we cannot specify, a priori, the logical form. See MacBride 2018 for an excellent discussion.

5. See Misak 2020.

6. King's College Archive FPR 5/5/434. In July 1927, Ramsey would invite Schlick to present a paper at the Moral Sciences Club - "The Meaning of Cognition." Schlick's wife accompanied him to Cambridge, and they got along very well with the Ramseys.

7. Christoph Limbeck-Lilineau uncovered this story for me.

8. Archives of Scientific Philosophy, University of Pittsburgh, Han Reichenbach Collection: ASP/ HR-016-42-16.

9. Archives of Scientific Philosophy, University of Pittsburgh, Han Reichenbach Collection: ASP/ HR-016-42-16.

10. Wittgenstein Collection, Brenner Archive: M31.

11. Vienna Circle Archives, Noord-Hollands Archief: 123/Wittg-1.

12. Archives of Scientific Philosophy, University of Pittsburgh: Rudolf Carnap Collection 025-72-06 42-01: 68, 769.

13. See Carnap, Hahn \& Neurath 1973 [1929].

14. The letter is published in McGuinness (2012: 158-61).

15. It's not clear that Ramsey's own account was satisfactory. In order to make mathematics a collection of tautologies, he had to introduce a range of entities to ensure that, when true, ' $a=b$ ' comes out true on every interpretation. But the introduction of such entities makes the tautologies that emerge nothing like the innocent, trivially true, tautologies that Wittgenstein took to constitute logic.

16. See Archives of Scientific Philosophy, University of Pittsburgh: 1983.01: 006-06-1; 1983.01: 006-06-07.

17. See Russell (1931: 477). 
18. It's unclear when Carnap acquired his copy of Braithwaite's volume, but there is evidence that it was not many years after its publication. There are extensive comments and annotations in Carnap's young hand, and another set in a more elderly hand, and enough years had passed so that Carnap, in the 1950s, forgot what was in it. See Misak 2020.

19. In Galavotti 1991.

20. Whether or not he went all the way to adopting a pragmatist account of truth, he certainly adopts a pragmatist account of meaning or content, in which equivalent beliefs have the same “causal properties" (FP: 44).

21. He also raised more particular problems, such as what is now known as the colour exclusion problem. See Misak 2020.

22. See Methven (2015: 113).

23. Archives of Scientific Philosophy, University of Pittsburgh: RC.1974.0: 102-13-53.

24. See Psillos (1999: 46).

25. See Carnap 1958; Hempel 1958.

26. See Archives of Scientific Philosophy, University of Pittsburgh: RC.1974.01: 102-13-53.

27. Archives of Scientific Philosophy, University of Pittsburgh: 1983.01: 006-02-03. (The strikethrough is Ramsey's.)

28. Archives of Scientific Philosophy, University of Pittsburgh: 003-30-05.

29. Vienna Circle Archives, Noord-Hollands Archief, \#114-Ram-4.

30. See Misak 2020 for more, especially about generalizations and scientific laws.

\section{ABSTRACTS}

Frank Ramsey (1903-1930) is usually taken to be sympathetic to the Vienna Circle's project. I will argue that this is not right. Ramsey was a pragmatist, and he put pragmatist objections to Wittgenstein's Tractatus, objections which also had the Vienna Circle as their target. Ramsey thought the Circle's position (like Wittgenstein's) was mistaken in that, instead of starting with human inquiry, it tried to construct the world out of elementary particulars and logic, and resulted in an unacceptable solipsism. This paper traces the trajectory of Ramsey's pragmatist thought, and its relationship to the early Wittgenstein and the Vienna Circle.

\section{AUTHOR}

\section{CHERYL MISAK}

University of Toronto

Cheryl.misak[at]utoronto.ca 